of the placenta was the pulseless and flabby state of the cord. When this was obtained, then each case could be treated on its own merits ; if there were hæmorrhage, more or less active interferenco. was required. If there were no hæmorrhage there really was no need: for active interference, and simple means, such as gentle friction or expression, would often cause the placenta to comie away.

MIr. WADDBLL (Newry), related a case which had occurred in his practice, in 1866. He was called to a woman in the sixth month of pregnancy, and found her in labour. She was delivered of a dead fœtus, the placenta of which, after it had become detached, he removed. At the same time he felt the movements of another child. This was retained, and the woman was delivered of a healthy boy at full term, three months afterwards. He believed that if he had been in too great a hurry to remove the first placenta and had employed the usual means for doing so, the second child would have been lost.

The Presidennt (Dr. Godson), considered that very different ideas were entertained as to the meaning of the terms "Expression of the placenta," and " Expectant method." $\mathrm{He}$ could not over-estimate the importance of placing the hand on the uteras immediately after the birth of the child, and keeping it there, if possible, until the separation of the placenta. Gentle kneading of the uterus to excite contractions was one thing, and forcing out the placenta, which invariably turned the membranes inside out, with a great tendency to leave some portions behind, was another. Such a plan was objectionable, and should only be had recourse to in cases of hrmorrhage or continued inertia, which the administration of ergot of rye and beef-tea, and, perhaps, a small quantity of stimulant, would not overcome. Compression of the uterus, after the removal of the placenta, to expel clots, was of great use; but, if the uterus could be coaxed to expel the placenta itself-a fair amount of patience being exercised-it was far better than forcibly expressing it.

\section{THE TREATMENT OF LUPUS.}

\section{Road in the Section of Medicine at the Fifty-Sccond Annual Meeting} of the British Medical Association.

BY J. HERBERT STOWERS, MI.D.,

Physician to Department for Skin Diseases, North-West London IIospital.

IN accordance with the excellent rule of our Association, that communications read at the sectional meetings should be both as concise and brief as possible, I do not desire to discuss at this time the whole subject of the treatment of lupus. So numerous, and indeed various, have been the suggestions in the past, that, until comparatively recently, the experience of dermatologists has not been sufficiently comllete to decide whether. gieater advantages are to be obtained from the use of caustics, or other methods.

My own opportunity of dealing with the disease has been consider. able enough to allow me to form some judgment as to the relative inelits of most of them; and it is on account of the fact that I have observed more satisfactory results by far from the combined use of the scoop and nitrate of silver, that I have resolved to ask your special consideration of the method of treating lupus by erasion or scraping.

I purposely refrain saying anything here concerning internal remedies, so necessary as they are to correct the general failure in health, or predisposition to the local development, neither can I stay to review the local treatments in their entirety.

The process of erasion advocated by Volkmann is carried out by means of a small hollow and elongated spoon, or scoop, with a moderately sharp edge, set in an ivory or bone handle. The special advantage is, that when the scoop is applied with considerable force, all the diseased tissue, or cell-growth, which is exceedingly vascular and friable, immediately breaks down, and is removed, while the healthy surrounding structures of the skin are too dense and fibrous to be included in the operation.

Those who have had experience of this method, will concur as to the remarkable way the soft, spongy, boggy tissue yields to the scoop, and how much more certainly can the extent and depth of the disease in this manner be estimatel. All the cases I have treated thus have been of long duration, and the new growth in each has existed over an extensive area.

The operation should not be undertaken except with the aid of an anæsthetic, for much of its after success depends upon the complete removal of every tubercle, and, consequently, occupies a considerable period of time. With so vascular a structure also, much hæmorrhage results which should be entirely arrested before thie solid nitrate of silver is used. I repeat-for it cannot be too carefully noted-that thorough eradication of the abnormal growth n!ust be secured before the scoop is laid aside. In several instances I have operated upos large masses of disease situated over the great vessels of the neck, and, despite the force required, I can truly assert that, with even moderatp care, no danger occurs of wounding them.

When the process of scraping is completed, and the hremorrhage arrested (local depletion being, doubtless, an aid to results), the serous discharge escaping from the wounds should be carefully soaked up with clean blotting-paper. Attention to this latter point will obviate the risk of the dissolved caustic running over the surrounding healthy integument, and so adding needlessly to the suffering of the patient.

It is necessary that the nitrate should be pushed deeply into the holes and interstices left by the instrument; in fact, it should be made to burrow into the tissues quite as extensively and deeply.

Considerable inflammation of course follows, which assists ultimate absorption ; but the intensity of the pain does not last nearly so long as that attending the use of other caustics.

The parts should be dressed with lint well saturated with carbolised oil, the next day more oil being allowed to run under the dressing. The second day after the operation, when suppuration has commenced, fresh carbolised oil-dressings should be applied, and so on daily. So severe is the smarting if water be used, that it is preferable, until the discharge is considerable, to cleanse the part by gently rubbing with lint dipped in olive-oil, to which a drop or two of carbolic acid may be added. Later, when the sloughs are separating, a weak carbolic acid lotion is advisable for the same purpose, and may with advantage be used with a syringe.

In the cases under my care, which have been, so far, attended with permanently good results, it was necessary to repeat the operation at intervals varying from six to eighteen months; indeed, in some, several repetitions have been compulsory. But I contend, and that very strongly, that, if every new tubercle be immediately attacked, the instances will be few and far between, if any, in which, with the addition of appropriate internal and constitutional treatment, the tendency to new development will not be outmatched.

The destructive results of this rebellious affection are too well known to require a word more in this direction ; suffice it to say that in five cases, at least, I have secured noses marked now with a relatively limited scarring, which would otherwise (if left without local treatment) have broken down by extending disease and secondary ulceration, to the production of irremediable and hideous deformities.

The natural tendency to recur must never be accepted as sufficient reason for not contending again and again with the disease until that age or condition of health be reached which will secure lasting and permanent immunity.

I would recommend, not less strongly, that any neighbouring tissue, while suspicious in character, though not readily breaking down under the scoop, should be freely submitted to multiple punctiform or linear scarification, combined with a liberal use of the solid nitrate of silver.

Three cases alone, taken from my note-book, will suffice to illustrate practically the value of the above treatment, and with these I conclude.

CASE 1.-Emily D., aged 20 in July 1883: Extensive lupus of nose. Residing at Chislehurst. Duration eight years. Four operations under ether: one in 1881 ; two in 1882; one in 1883 (February). No return up to present date. Cicatrices well formed, and healthy.

CASE II.-Anne K., aged 27 in 1877. Residing in Bedfordshire. Extensive lupus of cheek. Duration twenty years. Two operations under ether: one in January 1881 ; one in 1882 . No return up to pressent date. Parts look quite healthy.

CASE III.-Elizabeth C., aged 19 in 1880. Lupus of nose. Duration nine years. Three operations during 1880 and 1881. Perfect scar-tissue now remaining. No evidence of disease returning.

Bicarbonate of SodA in Tonsilitiris.-In the early stages of tonsillitis, before the pain of swallowing is excessive, Dr. G. Partagas alleges that bicarbonate of sode will arrest the inflammation. He makes the application in the following manner. The index finger being moistened, is charged with as thick a layer of the powder as will adhere to it; and is then introduced into the mouth and rubbed thoroughly over the inflamed tonsil. Five or six applications are thus made at intervals of five minutes. At the end of this time, Dr. Partagas has found that the patient will find the act of swallowing 1learly painless. When thus employed in the early stages, bicarbonate of soda will cut short the disease, and later will promote resolution. In hypertrophy of the tonsils, two or three applications of the powder each day will reduce the size of the glands very considerably in one or two months. 